Research Article:

\title{
First Reference Curve for Body Fat Percentage Among Schoolchildren of Babol in North of Iran: An International Comparison
}

\author{
Haleh Esmaili ${ }^{1}$, Mahmoud Hajiahmadi ${ }^{2}$ (D) Hoda Tavakoli ${ }^{3}$, Reza Ghadimi ${ }^{*}$ (I)
}

1. Social Determinants of Health Research Center, Health Research Institute, Babol University of Medical Sciences, Babol, Iran.

2. Non-Communicable Pediatric Disease Research Center, Health Research Institute, Babol University of Medical Sciences, Babol, Iran.

3. Student Research Center, Babol University of Medical Sciences, Babol, Iran.



chtition: Esmaili H, Hajiahmadi M, Tavakoli H, Ghadimi R. First Reference Curve for Body Fat Percentage Among Schoolchildren of Babol in North of Iran: An International Comparison. Journal of Pediatrics Review. 2018; 7(1):61-66. http://dx.doi.org/10.32598/ jpr.7.1.61

dol: : http://dx.doi.org/10.32598/jpr.7.1.61

Funding: See page 65

(c) Copyright: The Author(s)

\section{Article info:}

Received: 04 July 2017

First Revision: 22 July 2017

Accepted: 03 March 2018

Published: 01 January 2019

Keywords:

School children, Body fat percentage, Reference curves

\begin{abstract}
A B STRACT
Background: Several studies have developed sex-specific reference percentile curves for body fat percentage in children to be adopted in clinical surveys.

Objectives: This study aimed to develop acceptable percentile curves for body fat percentage in children in Babol, North of Iran, to assess childhood obesity.

Methods: Body fat percentile charts were created using bioelectrical impedance analysis of 7 to 11 years old schoolchildren from rural and urban parts of Babol. The obtained percentile charts were then smoothed.

Results: The findings showed that the mean fat percentages differed between boys and girls. The $50^{\text {th }}$ percentile curve was slightly higher for boys of 7-11 years, with a peak fat percentage of $22.50 \%$ at 11 years of age, whereas the mean fat percentage increased with age in 7 to 9 years old girls (16.8\%-22.05\%), reduced slightly from 9 years of age, and then peaked at $25.5 \%$ at 11 years.

Conclusions: This study provided reference curves for body fat percentage in the North Iranian children, who were found to have significantly high body fat percentage. It may be useful to further prepare national reference values and cut-off points for body fat percentage as a predictor of childhood obesity.
\end{abstract}

\section{Introduction}

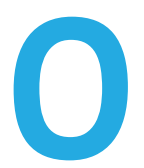

besity is a metabolic disorder determined based on the increase in Body Fat (BF) and considered as an important risk factor for several diseases (1). The increase in global obesity rates has tripled over the last three decades, and this growth has occurred across all ages, genders, races, and ethnicities $(2,3)$. Research has shown that on average, 43 million children aged $<5$ years are overweight worldwide, most of them live in developing countries (35 million vs. 8 million). Among school chil-

* Corresponding Author:

Reza Ghadimi, MD., Ph.D

Address: Department of Social Medicine \& Health Babol University of Medical Sciences, Ganj Afrooz Ave., Babol, Iran.

Tel: +98 (911) 32197667

E-mail: Rezaghadimi@yahoo.com 
dren in North of Iran, the total prevalence of overweight and obesity (approximately 26\%) is reportedly similar between boys and girls (3). Lifestyle and socioeconomic status are the most important factors affecting obesity. Physical activity and dietary intake are the most important parts of lifestyle that regulate the use of body's energy in the prevention and treatment of obesity (4-8). Body Mass Index (BMI) is widely used as BF indicator in most studies on overweight and obesity (9).

Because the ratio of fat/lean tissue varies among people, the combination of height and weight in the form of BMI is not a suitable indicator to measure the amount of BF (10). Moreover, BMI does not distinguish between excess fat mass and fat-free mass (3); thus, BF percentage (BF\%) in obese children cannot be known through BMI screening alone (3). Therefore, it is necessary to more accurately estimate the prevalence of childhood overweight and obesity and to take proper measures to reduce them because they can lead to health problems, such as cardiovascular diseases, hypertension, and diabetes (11).

Evaluating the BF curve is one of the most important approaches for monitoring growth, evaluating physical health, and estimating BF in children without ruling out the influence of dietary patterns and cultural and social factors. Bioelectrical Impedance Analysis (BIA) can be a suitable tool to measure fat mass because it is cheap and simple to use. BF\% higher than $85^{\text {th }}$ and $95^{\text {th }}$ percentiles is considered as overweight and obesity, respectively (12). Despite the importance of regulating BF for physical well-being, limited data on $\mathrm{BF} \%$ are available (13), and to our knowledge, no research has been conducted so far in the Middle East and Iran for developing a BF curve; therefore, this study aimed to determine acceptable percentile curves for BF\% in children to assess childhood obesity.

\section{Methods}

This cross-sectional (descriptive-analytical) study in cluded 4083 students aged 7-11 years (1777 boys and 2306 girls) studying in primary schools (one to five grades levels) of Babol, Mazandaran Province, North of Iran. A multistage cluster sampling was conducted with the help of the Department of Education in Babol to prepare a list of urban and rural schools. Based on the geographical locations, six and five primary school pupils were selected as clusters. In addition, 14 rural schoolchildren of different grade levels were chosen according to geographical distribution, and then all children from each school were assessed based on anthro- pometric indices by a trained research team (Medical, Nursing, and Midwifery students), principals, and health teachers (14).

Anthropometric parameters that were assessed included weight, height, and BF\%. Weight was measured under standard conditions using Omron digital scale model BF-511 with a precision of $0.1 \mathrm{~kg}$ in the morning with light clothing before eating breakfast. A seca stadiometer with a precision of $0.1 \mathrm{~cm}$ was used to measure the height of students in a standing position without shoes. BIA, which is a safe, simple, quick, and relatively inexpensive method to measure body composition, especially in epidemiological studies (15-19), was used to measure BF\% with the analyzer Omron BF504.

In the BIA method, two electrodes are located on the dorsum of both feet and two electrodes on the dorsum of both hands; one electrode of each pair acts as the input and the other as the output. The resistance to electric current is then measured via these electrodes. Because lean tissue is a good conductor of electricity, people who store more fat have more voltage drop between the wrist and feet $(18,20)$. Sex, age, height, and weight data of each person were entered in the scale, BF\% was calculated using the data entered in the scale, and the amount of voltage drop was then used to plot BF\% curves based on age and sex. All data were entered in SPSS-18 and were analyzed using descriptive statistics and the Independent sample t test. $P$ value of $<0.05$ was considered as statistically significant. The plotted graphs were smoothed. Written invitations were sent to principals and parents of all schoolchildren to obtain their signed informed consent for participation in the study. The study protocol was approved by the Ethics Committee of Babol University of Medical Sciences.

\section{Results}

This study included 4083 school children (1777 [43.5\%] boys and 2306 [56.5\%] girls) aged 7-11 years from Babol City. The age of $13.4 \%, 24.6 \%, 25.2 \%, 21.4 \%$, and $15.4 \%$ of school children was 7, 8, 9, 10, and 11 years, respectively. In general, BF\% was significantly higher among girls in all age groups $(P<0.05)$, except in the 7 -year age group in which boys had a significantly higher BF\% than girls $(P<0.01)$ (Table 1$)$.

The results showed that the mean BF\% was almost constant in boys from 7 to 8 years of age and that it significantly increased with age in 8 to 11 years old boys $(P<0.001)$. The mean $B F \%$ in girls increased from 7 to 9 years of age and slightly decreased from 9 to 10 years 
Table 1. The means and standard deviations of body fat percentage of 7 to 11 years old primary school children

\begin{tabular}{cccc}
\hline & & Mean \pm SD & \\
\cline { 2 - 3 } Age (Year) & Girls & Boys & 0.002 \\
\hline $7.00-7.99$ & $18.18 \pm 7.47$ & $20.17 \pm 7.19$ & 0.013 \\
\hline $8.00-8.99$ & $21.52 \pm 8.66$ & $20.23 \pm 7.65$ & 0.004 \\
$9.00-9.99$ & $22.58 \pm 8.50$ & $21.06 \pm 7.95$ & 0.476 \\
$10.00-10.99$ & $22.52 \pm 8.11$ & $22.12 \pm 8.12$ & 0.420 \\
$11.00-11.99$ & $24.56 \pm 8.81$ & $23.93 \pm 9.79$ & $21.34 \pm 8.17$ \\
\hline Total & $22.07 \pm 8.57$ & & 0.006 \\
\hline
\end{tabular}

P-value less than 0.05 was considered significant.

Journal of Pediatrics Review

(from $22.58 \% \pm 8.50 \%$ at 9 years to $22.52 \% \pm 8.11 \%$ at 10 years); it further significantly increased from 10 years $(\mathrm{P}<0.001)$ (Table 2$)$. The boys showed relatively flat $50^{\text {th }}$ percentile curve from approximately $20.0 \%$ BF over the entire age range, with a peak $\mathrm{BF} \%$ of $22.50 \%$ at 11 years. The $50^{\text {th }}$ percentile curve of girls showed a different pattern with fluctuations, starting from $16.80 \%$ BF at 7 years to $25.50 \%$ BF at 11 years, with a peak of $22.05 \%$ at 9 years and a decrease $(21.30 \%)$ at 10 years.

The $5^{\text {th }}$ percentile curve of boys decreased after 7 years of age, then increased till 9 years, and significantly reduced after 10 years of age (Figure 1). In contrast, the $5^{\text {th }}$ percentile curve of girls showed an upward pattern with a marginal decline in BF\% after 10 years of age. The $95^{\text {th }}$ and $50^{\text {th }}$ percentile curves were similar in girls but showed different patterns in boys. The $50^{\text {th }}$ percen- tile curve of boys showed a marginally increase in BF\% from 7 to 11 years of age, but the $95^{\text {th }}$ percentile curve showed a reduction in $\mathrm{BF} \%$ at 8 and 10 years and a peak of $40.59 \%$ at 11 years (Figure 1).

To define clinical cut-offs that are widely consistent with the BMI cut-offs, our current data were adapted using International Obesity Task Force-and World Health Organization-defined reference cut-offs, and the nearest BF percentile cut-offs were set. The $75^{\text {th }}$ and $85^{\text {th }}$ percentiles provided a close approximation to the overweight and obese boundaries.

\section{Discussion}

The findings of the present study showed that the mean BF\% was not similar between North Iranian boys

Table 2. Body fat percentiles of boys and girls based on age

\begin{tabular}{|c|c|c|c|c|c|c|c|c|c|c|}
\hline \multicolumn{2}{|c|}{ Age (Year) } & $2^{\text {nd }}$ & $5^{\text {th }}$ & $10^{\text {th }}$ & $25^{\text {th }}$ & $50^{\text {th }}$ & $75^{\text {th }}$ & $90^{\text {th }}$ & $95^{\text {th }}$ & $98^{\text {th }}$ \\
\hline \multirow{5}{*}{ Boys } & 7.00-7.99 & 7.89 & 9.40 & 10.82 & 15.80 & 19.10 & 23.80 & 30.60 & 35.04 & 36.50 \\
\hline & 8.00-8.99 & 7.80 & 8.85 & 11.30 & 14.40 & 19.00 & 25.25 & 31.50 & 34.25 & 36.15 \\
\hline & $9.00-9.99$ & 8.10 & 9.98 & 11.74 & 14.82 & 19.85 & 26.87 & 32.80 & 35.93 & 37.30 \\
\hline & 10.00-10.99 & 9.20 & 10.14 & 12.38 & 16.00 & 21.20 & 27.80 & 34.52 & 36.66 & 37.90 \\
\hline & 11.00-11.99 & 8.37 & 9.11 & 11.40 & 15.55 & 22.50 & 32.60 & 36.98 & 40.59 & 42.12 \\
\hline \multirow{5}{*}{ Girls } & 7.00-7.99 & 6.52 & 7.36 & 9.37 & 12.97 & 16.80 & 23.12 & 29.00 & 33.08 & 35.43 \\
\hline & $8.00-8.99$ & 8.10 & 9.18 & 11.27 & 14.70 & 20.20 & 28.27 & 34.30 & 37.21 & 38.77 \\
\hline & $9.00-9.99$ & 8.34 & 9.65 & 12.07 & 15.90 & 22.05 & 28.77 & 35.06 & 37.01 & 38.51 \\
\hline & 10.00-10.99 & 10.10 & 10.70 & 12.70 & 16.50 & 21.30 & 28.60 & 34.32 & 36.86 & 38.30 \\
\hline & 11.00-11.99 & 9.02 & 10.50 & 13.18 & 17.50 & 25.50 & 31.50 & 36.60 & 39.24 & 40.71 \\
\hline
\end{tabular}

The $5^{\text {th }}, 90^{\text {th }}$ and $95^{\text {th }}$ percentiles define the cut offs for under fat, over fat and obese.

Journal of Pediatrics Review 

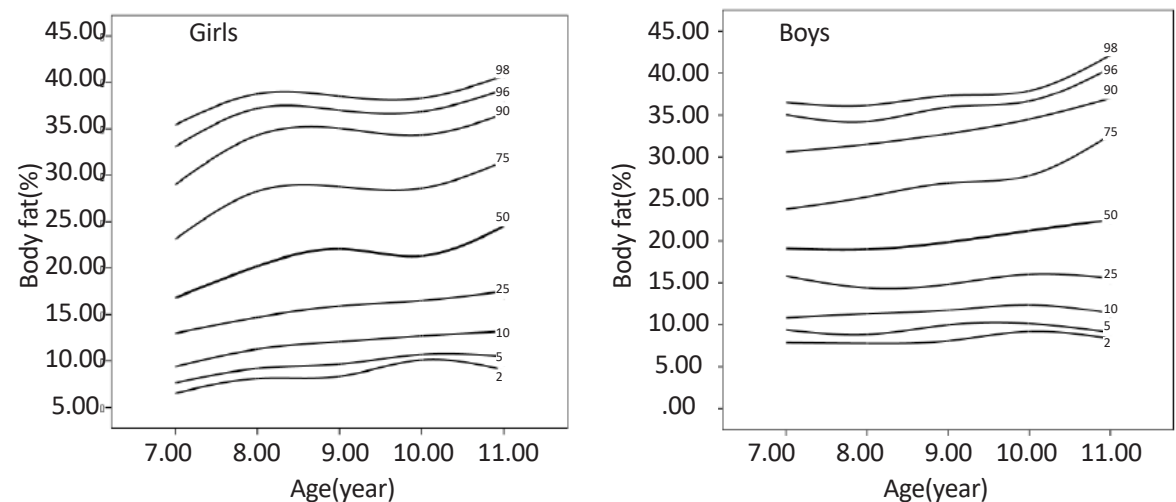

Figure 1. Fat percentiles of 7-11 -Year- old schoolchildren of Babol based of Age

Journal of Pediatrics Review

and girls. The $50^{\text {th }}$ percentile curve showed a slight increase in BF\% in boys from 7 to 11 years of age, whereas the mean $\mathrm{BF} \%$ increases in girls from 7 to 9 years of age and then slightly reduced with age from 9 years. Among 3 to 18 years old German children, Schwandt et al. reported that in contrast to our study results on girls, the BF\% curve increased with age, whereas similar to our study results on boys, it increased from 5 to 11 years of age and then gradually decreased (20). Moreover, 7 to 11 years old American boys and girls reportedly show a similar pattern of BF\% curve, which increases with age (13). In addition, a study on Turkish children indicated that BF\% curve increases in boys from 7 to 10 years of age and then declines from 10 to 11 years of age, whereas the curve in girls shows incremental in- creases at a constant rate up to 11 years of age (21). Boys and girls in southern England also show different BF\% curves, with a trend of incremental increases at a constant rate in girls up to 10 years of age and boys up to 10 years of age, followed by a decrease with age (3).

Among Chinese children aged 6-18 years, Sung et al. found that the BF\% curve is constant in boys across all age groups, whereas it shows an increasing trend in girls (22). Kirang et al. reported that the pattern of BF\% curve differs between Korean boys and girls, with fat mass showing a decreasing trend in boys and a gradual increase with age in girls (23). The results of our study showed that the mean BF\% was less in 7-year-old girls than in same-age boys, whereas it was constantly higher
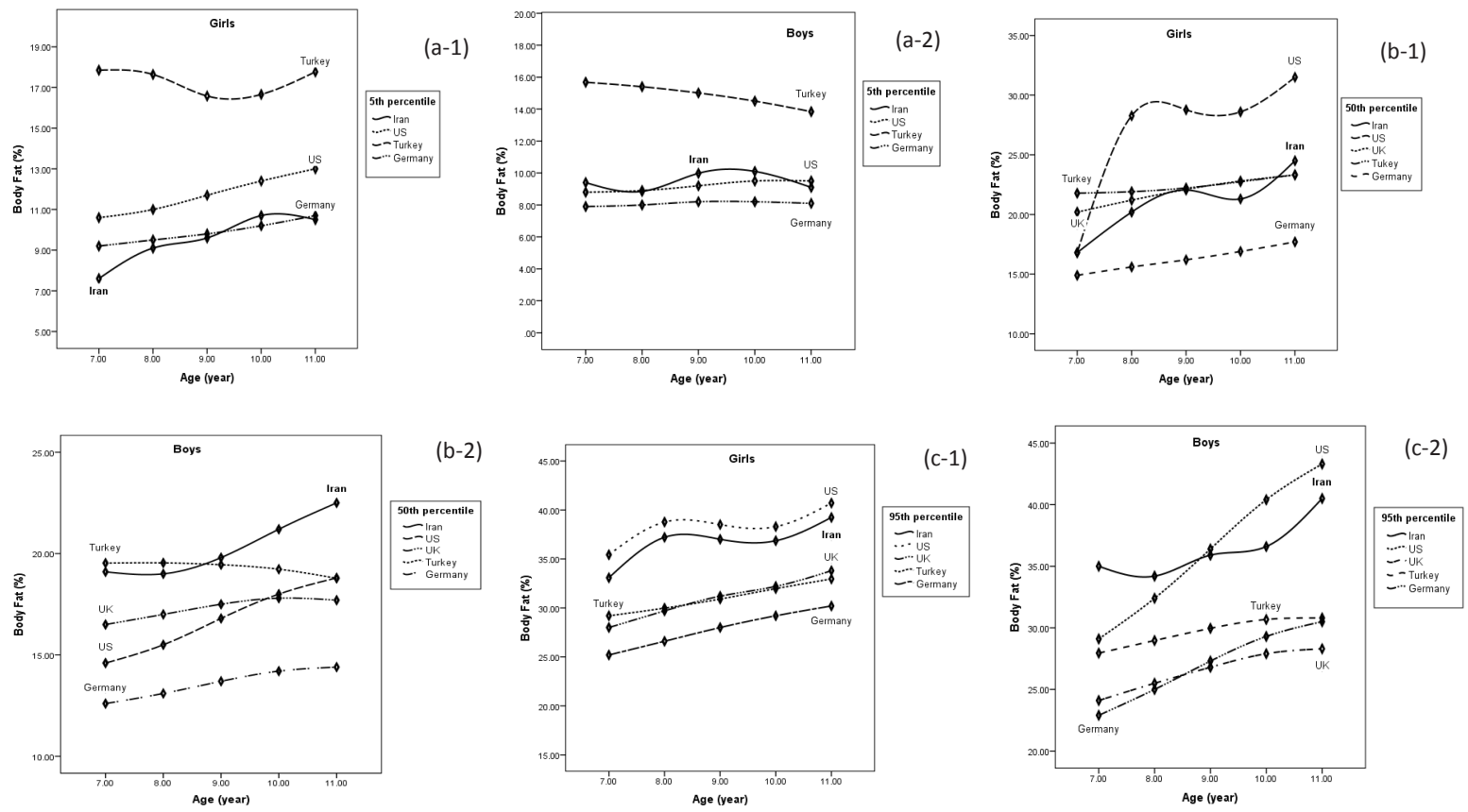

Journal of Pediatrics Review

Figure 2. $5^{\text {th }}(\mathrm{a}), 50^{\text {th }}(\mathrm{b})$ and $95^{\text {th }}$ (c) percentiles of body fat according to age and gender in Iran, UK, US, Turkey and Germany 
in girls than in boys from 8 years of age. Ogden et al. found that the fat distribution pattern differs between American boys and girls, with BF\% higher in girls than in boys in most age groups, which continuously increases with age in girls (24). Similarly, in a study on children from Northern Greece, Papandrenu et al. reported that the $\mathrm{BF} \%$ is permanently higher in girls than in boys across all age groups (25).

A comparison with the percentile charts of British, Turkish, German, and American children revealed that in the $5^{\text {th }}$ percentile curves of boys and girls show a progressive trend in $\mathrm{BF} \%$. In general, the $5^{\text {th }}$ percentile curve is higher among north Iranian boys than among German boys, showing a progressive increase at 9 and 10 years. This curve is also similar to that of American boys with some differences: the curve of American boys increases gradually, whereas that of Iranian boys is higher at 9-10 years and then decreases to the minimum at 11 years.

The $5^{\text {th }}$ percentile curve of Iranian girls shows a different pattern, which is close to that of German girls; it starts with a lower BF\% than that in the German curve at 7 years and then largely overlaps with it until 11 years of age. In addition, the $5^{\text {th }}$ percentile curve of Iranian girls is generally lower than that of Turkish and American girls (Figure $2 \mathrm{a}, 2 \mathrm{~b}$ ). The $50^{\text {th }}$ percentile curve of Iranian boys is largely close to that of Turkish boys with minimum differences till 9 years of age. At this point, the curve of Iranian boys is higher than that of British, American, and German boys. Further, the pattern of the $50^{\text {th }}$ percentile curve of Iranian girls is different from that of British and German girls but similar to that of American girls. However, the $50^{\text {th }}$ percentile curve of American girls is significantly higher than that of Iranian girls (Figure 2c, 2d). Furthermore, the $95^{\text {th }}$ percentile curve of Iranian and American girls showed similar patterns, with the American curve being marginally higher than the Iranian curve.

In general, Iranian girls have higher BF\% than British, Turkish, and German girls, with different patterns of curves. The pattern of $95^{\text {th }}$ percentile curve of Iranian boys differed from that of Iranian girls as well as from that of boys of other countries. The $95^{\text {th }}$ percentile curves of boys from other countries (UK, US, Germany, and Turkey) show a consistent increase from 7 to 11 years of age with different slopes. Although the $95^{\text {th }}$ percentile curve of Iranian boys showed an upward trend overall, it declined from 7 to 8 and 9 to 10 years of age (Figure 2e, 2f). The differences in the shape of BF percentile curves among different countries are due to genetic factors, lifestyle habits, ethnicity, different sam- pling methods, and the BIA model used, in addition to other unknown factors (22).

\section{Conclusion}

In conclusion, this study provided reference BF\% curves for Iranian children, which were found to be significantly higher than those for children from other countries. Reference percentiles, such as $85^{\text {th }}$ or $95^{\text {th }}$ percentile, may not be appropriate for use as overweight and obesity thresholds. However, different ethnicity, sampling methods, and BIA models result in different curves with different results that may not be interchangeable. Therefore, future research is warranted to identify reliable cut-off values.

\section{Ethical Considerations}

\section{Funding}

This research project received financial support from the Research Vice Chancellor of Babol University of Medical Sciences.

\section{Conflict of interest}

The authors declared no conflict of interest.

\section{Acknowledgements}

The authors thank all student participants, parents, school principals, teachers, and staff members for their utmost corporation in this study. The authors thank Dr. Evangeline Foronda for English editing.

\section{References}

1. Colombo O, Villani S, Pinelli G, Trentani C, Baldi M, Tomarchio $\mathrm{O}$, et al. To treat or not to treat: Comparison of different criteria used to determine whether weight loss is to be recommended. Nutrition Journal. 2008; 7(5):1-7. [DOI:10.1186/1475-2891-7-5]

2. Eissa MA, Gunner KB. Evaluation and management of obesity in children and adolescents. Journal of Pediatric Health Care. 2004; 18(1):35-8. [DOI:10.1016/j.pedd hc.2003.11.002]

3. Ghadimi R, Asgharzadeh E, Sajjadi P. Obesity among elementary schoolchildren: A growing concern in the North of Iran, 2012. International Journal of Preventive Medicine. 2015; 6:99. [PMID] 
4. Kelishadi R, Ardalan G, Gheiratmand R, Gouya MM, Razaghi EM, Delavari A, et al. Association of physical activity and dietary behaviours in relation to the body mass index in a national sample of Iranian children and adolescents: CASPIAN Study. Bulletin of the World Health Organization. 2007; 85(1):19-26. [DOI:10.2471/BLT.06.030783] [PMID] [PMCID]

5. Tol A, Tavassoli E, Shariferad GR, Shojaeezadeh D. Healthpromoting lifestyle and quality of life among undergraduate students at school of health, Isfahan university of medical sciences. Journal of education and health promotion. 2013; 2:11. [DOI:10.4103/2277-9531.108006]

6. Lee HA, Lee WK, Kong KA, Chang N, Ha EH, Hong YS, et al. The effect of eating behavior on being overweight or obese during preadolescence. Journal of Preventive Medicine and Public Health. 2011; 44(5):226. [DOI:10.3961/ jpmph.2011.44.5.226] [PMID] [PMCID]

7. Steinbeck KS. The importance of physical activity in the prevention of overweight and obesity in childhood: A review and an opinion. Obesity Reviews. 2001; 2(2):117-30. [DOI:10.1046/j.1467-789x.2001.00033.x] [PMID]

8. Lahti-Koski M, Pietinen P, Heliövaara M, Vartiainen E. Associations of body mass index and obesity with physical activity, food choices, alcohol intake, and smoking in the 1982-1997 FINRISK Studies. The American Journal of Clinical Nutrition. 2002; 75(5):809-17. [DOI:10.1093/ajcn/75.5.809] [PMID]

9. Ezzati M, Vander Hoorn S, Lopez AD, Danaei G, Rodgers A, Mathers CD, Murray CJ. Comparative quantification of mortality and burden of disease attributable to selected risk factors. In Lopez AD, editor, Global burden of disease and risk factors. New York: Oxford University Press; 2006.

10. Daniels SR. The consequences of childhood overweight and obesity. The Future of Children. 2006; 16(1):47-67. [DOI:10.1353/foc.2006.0004] [PMID]

11. Eisenkölbl J, Kartasurya M, Widhalm K. Underestimation of percentage fat mass measured by bioelectrical impedance analysis compared to dual energy X-ray absorptiometry method in obese children. European Journal of Clinical Nutrition. 2001; 55(6):423-9. [DOI:10.1038/sj.ejcn.1601184] [PMID]

12. Cole TJ, Lobstein T. Extended international (IOTF) body mass index cut-offs for thinness, overweight and obesity. Pediatric Obesity. 2012; 7(4):284-94. [DOI:10.1111/j.20476310.2012.00064.x] [PMID]

13. Laurson KR, Eisenmann JC, Welk GJ. Body fat percentile curves for US children and adolescents. American Journal of Preventive Medicine. 2011; 41(4):S87-S92. [DOI:10.1016/j.amepre.2011.06.044] [PMID]

14. Fathi $M$, Hajiahmadi $M$, Esmaili $H$, Ghadimi R. Northern Iranian Growth Chart for 7-11 years old children: How Different from the Existing International Reference Curves. Eastern Mediterranean Health Journal (in press).
15. Kettaneh A, Heude B, Lommez A, Borys JM, Ducimetière $P$, Charles MA. Reliability of bioimpedance analysis compared with other adiposity measurements in children: The FLVS II Study. Diabetes \& Metabolism. 2005; 31(6):534-41. [DOI:10.1016/S1262-3636(07)70228-8]

16. Tyrrell V, Richards G, Hofman P, Gillies G, Robinson E, Cutfield W. Foot-to-foot bioelectrical impedance analysis: A valuable tool for the measurement of body composition in children. International Journal of Obesity. 2001; 25(2):2738. [DOI:10.1038/sj.ijo.0801531] [PMID]

17. Houtkooper LB, Lohman TG, Going SB, Howell WH. Why bioelectrical impedance analysis should be used for estimating adiposity. The American Journal of Clinical Nutrition. 1996; 64(3):436S-48. [DOI:10.1093/ajcn/64.3.436S] [PMID]

18. Ward LC. Segmental bioelectrical impedance analysis: An update. Current Opinion in Clinical Nutrition \& Metabolic Care. 2012; 15(5):424-9. [DOI:10.1097/ MCO.0b013e328356b944] [PMID]

19. Mann J, Truswell S. Essentials of human nutrition. Oxford: Oxford University Press; 2012.

20. Schwandt P, von Eckardstein A, Haas GM. Percentiles of percentage body fat in german children and adolescents: An international comparison. International Journal of Preventive Medicine. 2012; 3(12):846. [DOI:10.4103/20087802.104855] [PMID] [PMCID]

21. Kurtoglu S, Mazicioglu MM, Ozturk A, Hatipoglu N, Cicek B, Ustunbas HB. Body fat reference curves for healthy Turkish children and adolescents. European Journal of Pediatrics. 2010; 169(11):1329-35. [DOI:10.1007/s00431-010-12254] [PMID]

22. Sung RY, So H, Choi K, Li AM, Yin J. Body fat measured by bioelectrical impedance in Hong Kong Chinese children. Hong Kong Medical Journal. 2009; 15(2):110-7. [PMID]

23. Kim K, Yun SH, Jang MJ, Oh KW. Body fat percentile curves for Korean children and adolescents: A data from the Korea National Health and Nutrition Examination Survey 20092010. Journal of Korean Medical Science. 2013; 28(3):4439. [DOI:10.3346/jkms.2013.28.3.443] [PMID] [PMCID]

24. Borrud LG, Flegal KM, Freedman DS, Li Y, Ogden CL. Smoothed percentage body fat percentiles for US children and adolescents, 1999-2004. Hyattsville: National Center for Health Statistics; 2011.

25. Papandreou D, Malindretos P, Rousso I. First body fat percentiles for 607 children from Thessaloniki-Northern Greece. Hippokratia. 2010; 14(3):208. [PMID] [PMCID] 